\title{
Tracheal Fistula
}

National Cancer Institute

\section{Source}

National Cancer Institute. Tracheal Fistula. NCl Thesaurus. Code C78641.

An abnormal communication between the trachea and another org an or anatomic site. 